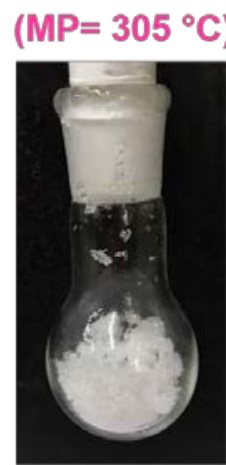

(ChCl)

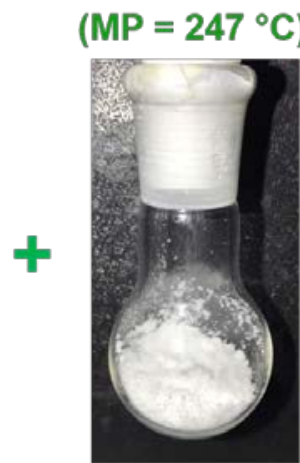

$(\mathrm{SnCl})_{2}$

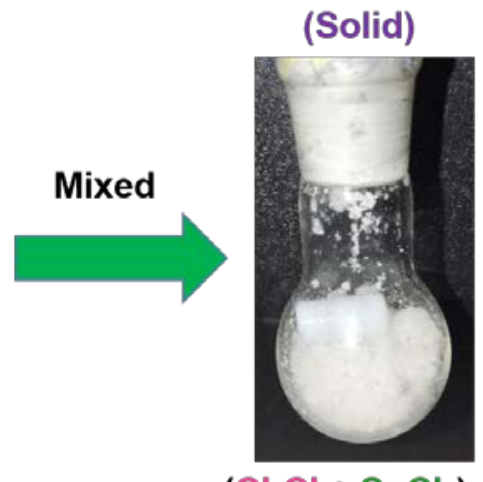

$\left(\mathrm{ChCl}+\mathrm{SnCl}_{2}\right)$

(1:2 Molar ratio)

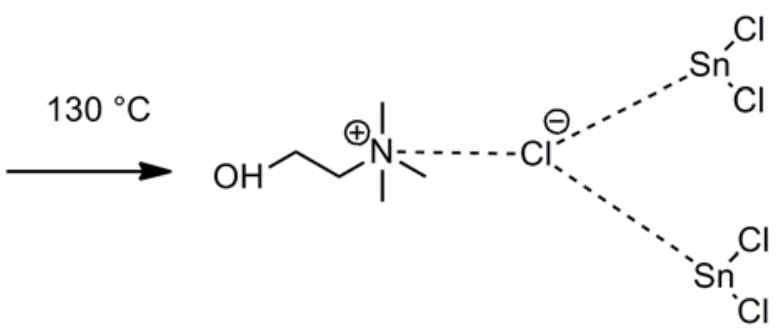

17 Figure S1. Photographs of $\mathrm{ChCl}, \mathrm{SnCl}_{2}$, mixture of $\mathrm{ChCl}$ and $\mathrm{SnCl}_{2}$, and deep eutectic

18 solvent. 


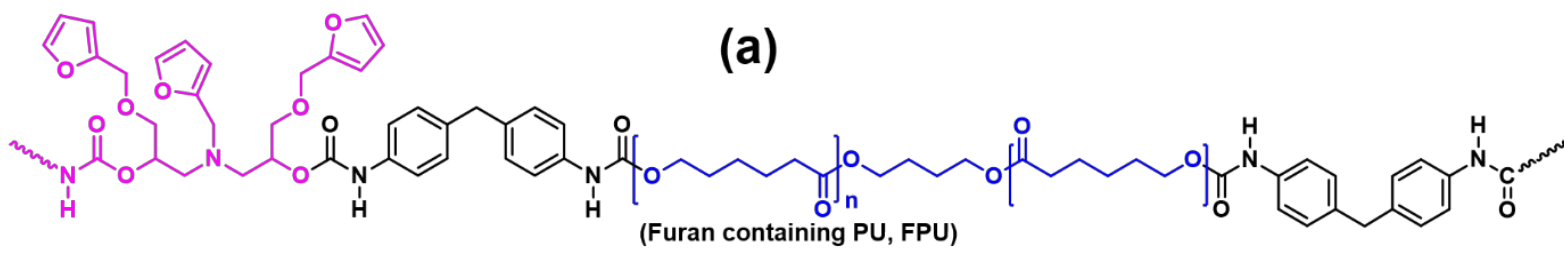

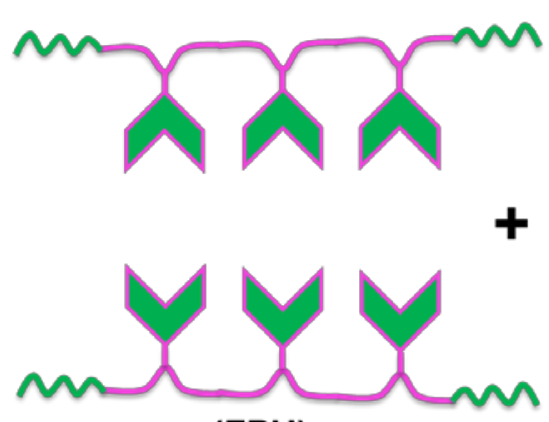

(FPU)

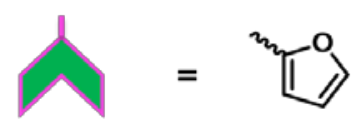

(b)

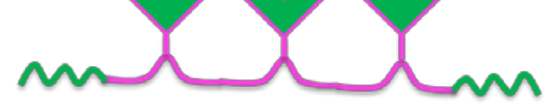

(FPU-BM)

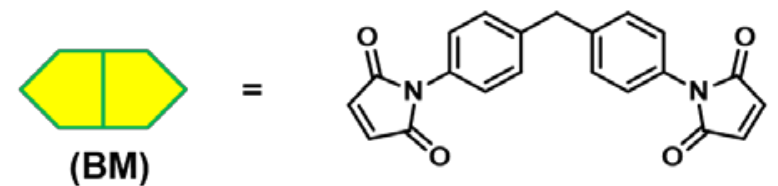

22 Scheme S2. Schematic representation of furan containing PU (FPU, reference PU without disulfide moiety, a) and its DA adduct with BM (FPU-BM, b).

\section{$24{ }^{1} \mathrm{H}-\mathrm{NMR}$ of chain extender (APDS-FGE diol) prepared using toluene}

25 When DES was replaced by toluene, the conversion of the reaction of between APDS and FGE

26 was very low. Figure S5 represents the ${ }^{1} \mathrm{H}-\mathrm{NMR}$ spectra of APDS and APDS-FGE diol

27 prepared using toluene as solvent. The conversion was calculated using peak area of the

28 resonances for aromatic protons (b \& $b_{1}$, Figure S5) and found to be $21 \%$. 


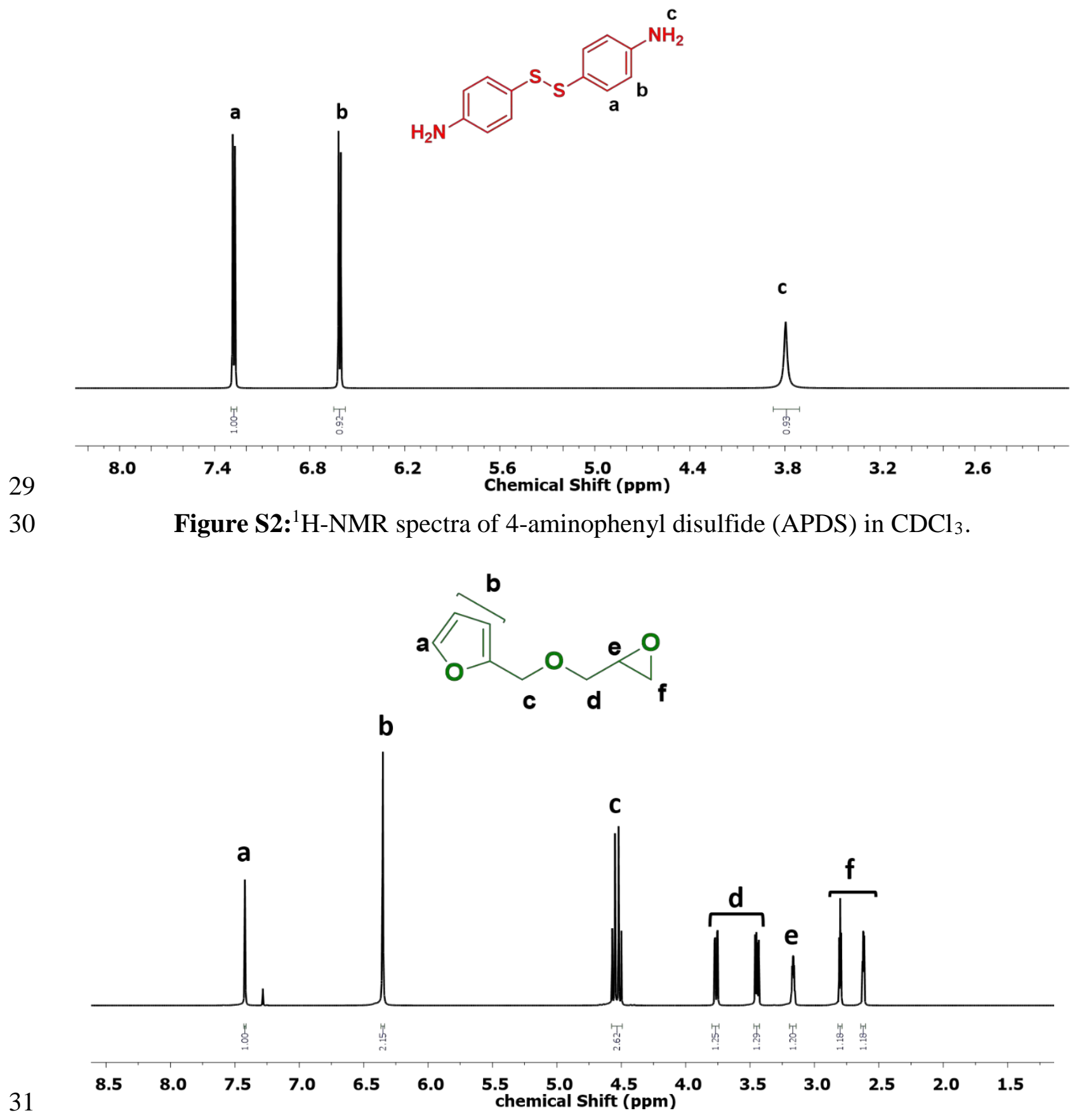

Figure S3: ${ }^{1} \mathrm{H}-\mathrm{NMR}$ spectra of furfuryl glycidyl ether (FGE) in $\mathrm{CDCl}_{3}$. 


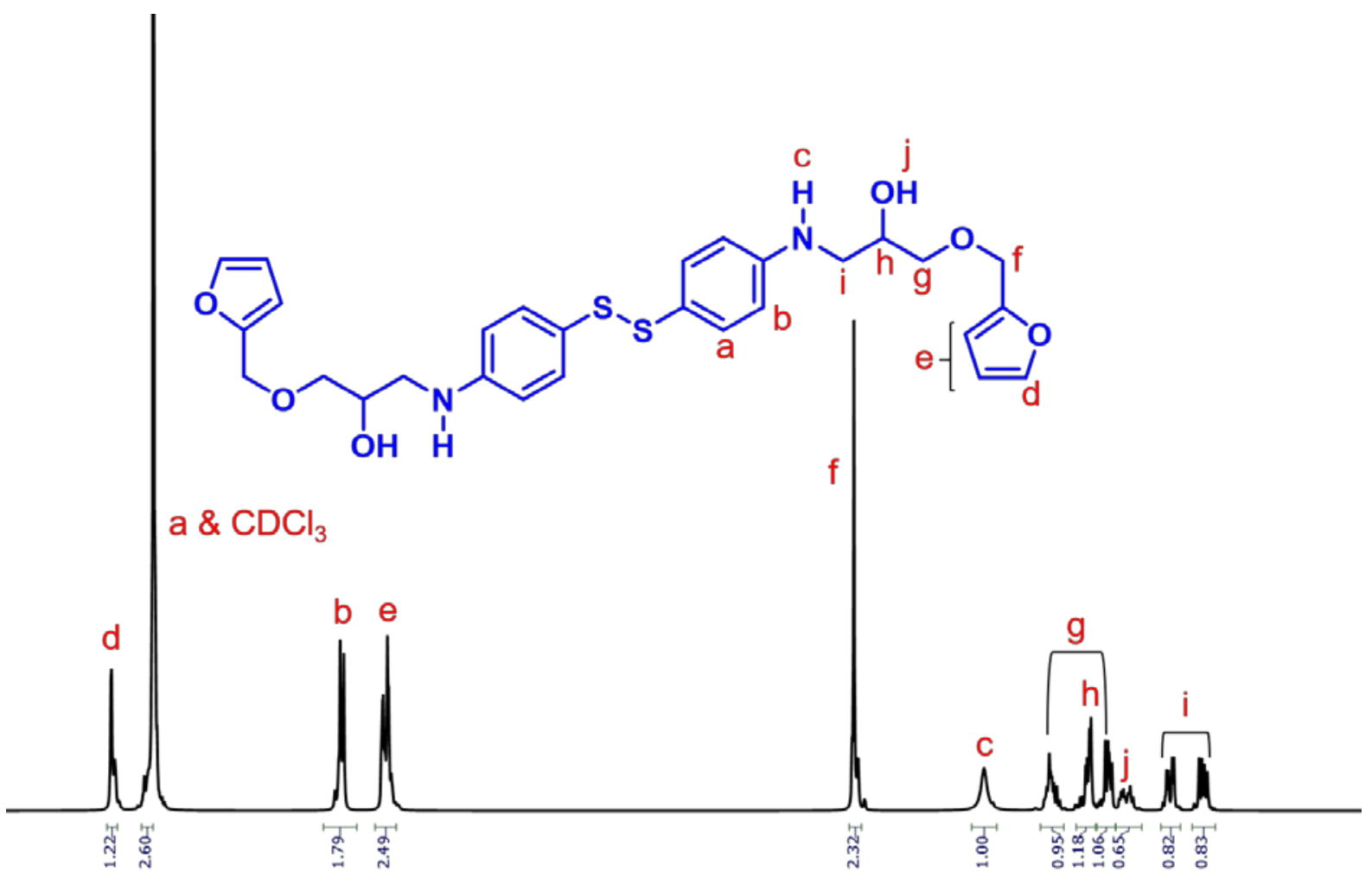

37 Figure S5: ${ }^{1} \mathrm{H}$-NMR spectra of 4-aminophenyl disulfide (APDS) and chain extender (APDS38 FGE diol, prepared using toluene) in $\mathrm{CDCl}_{3}$. Chemical Shift (ppm)

Figure S4: ${ }^{1} \mathrm{H}-\mathrm{NMR}$ spectra of APDS-FGE diol in $\mathrm{CDCl}_{3}$.

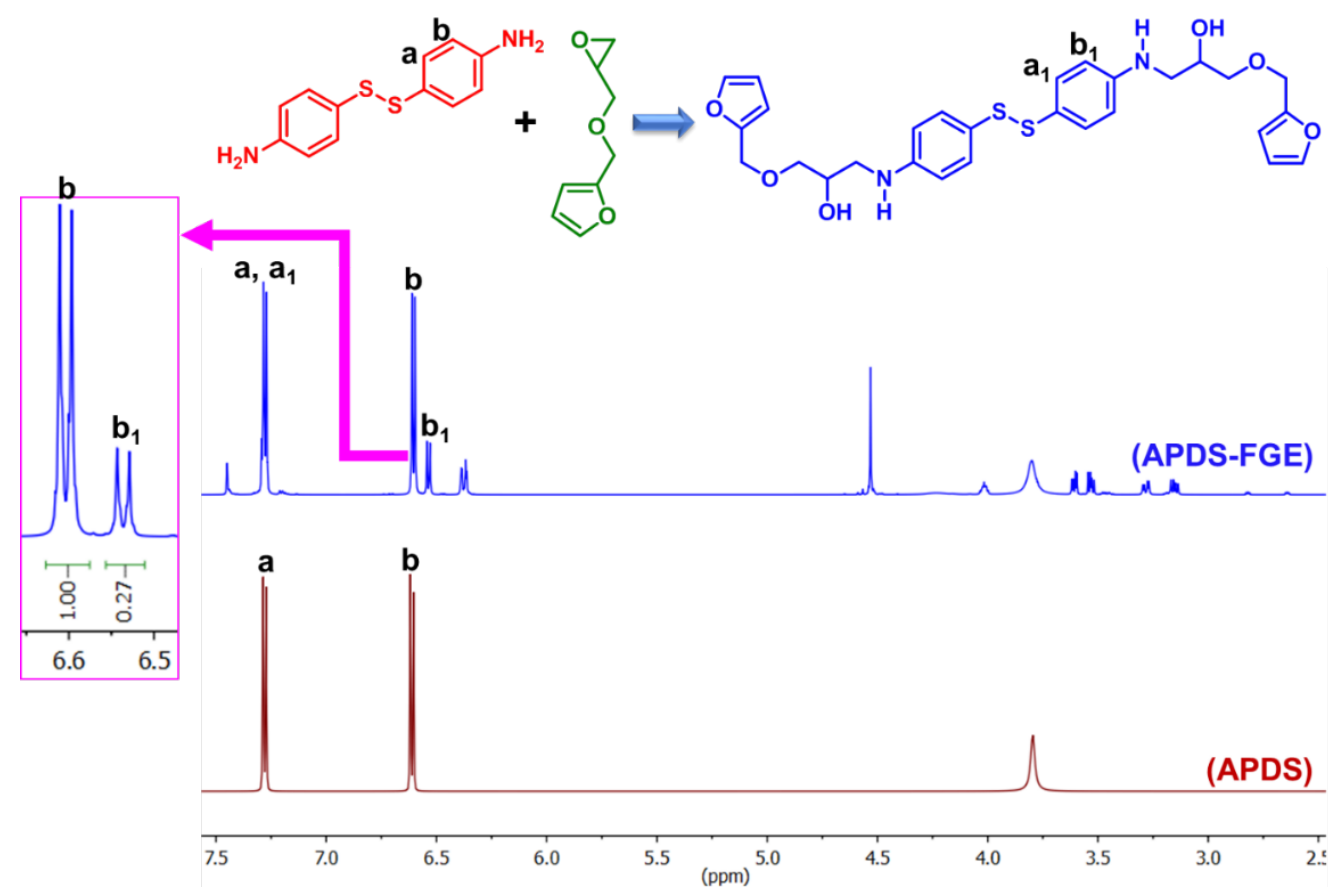

$\begin{array}{llllllllllllllllllllllllllll}7.8 & 7.6 & 7.4 & 7.2 & 7.0 & 6.8 & 6.6 & 6.4 & 6.2 & 6.0 & 5.8 & 5.6 & 5.4 & 5.2 & 5.0 & 4.8 & 4.6 & 4.4 & 4.2 & 4.0 & 3.8 & 3.6 & 3.4 & 3.2 & 3.0 & 2.8 & 2.1\end{array}$ 

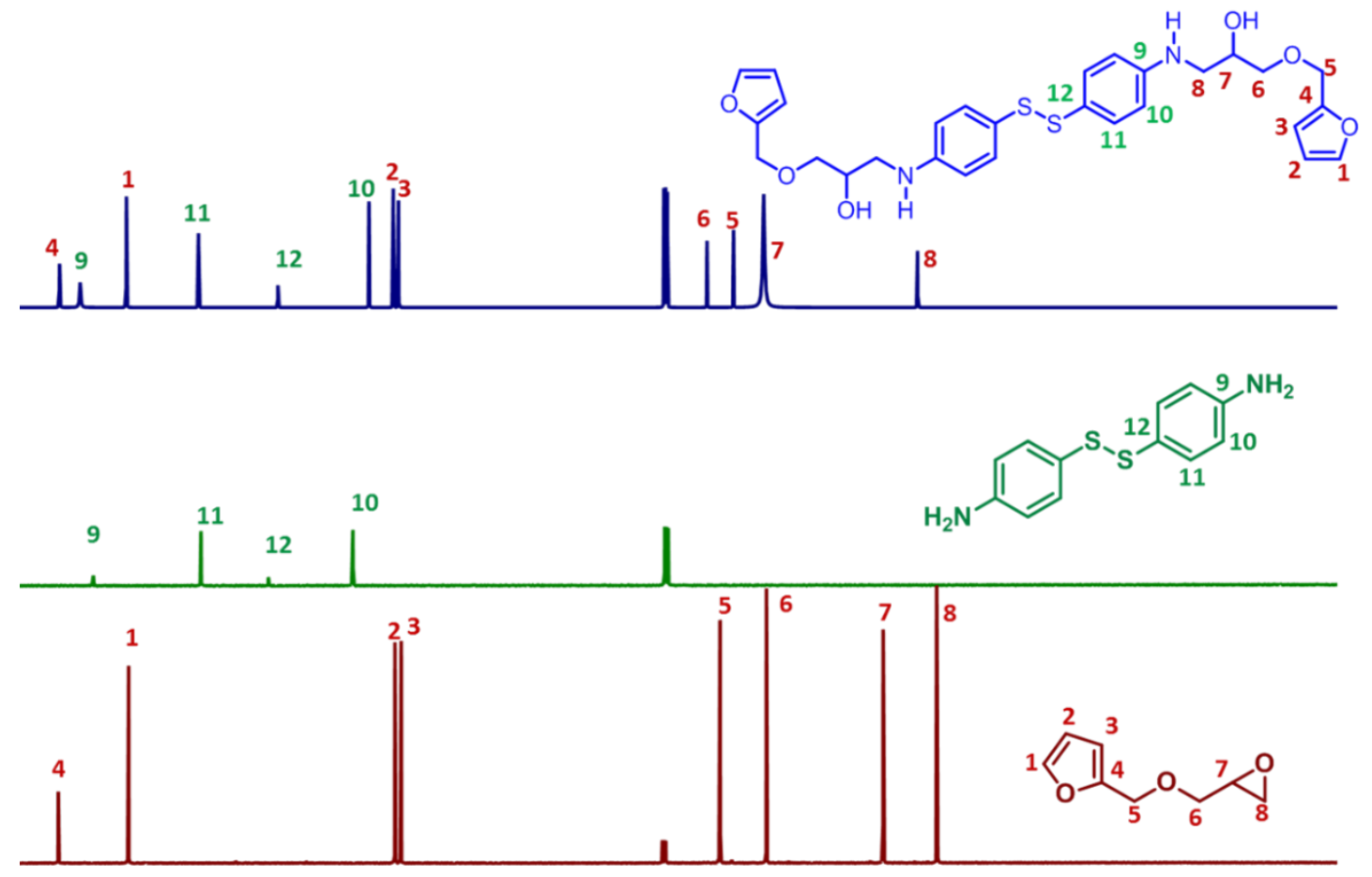

40 Figure S6. ${ }^{13} \mathrm{C}$-NMR spectra of 4-aminophenyl disulfide (APDS), furfuryl glycidyl ether 41 (FGE) and chain extender (APDS-FGE diol, prepared using DES) in $\mathrm{CDCl}_{3}$.

(TDS)

(APDS)
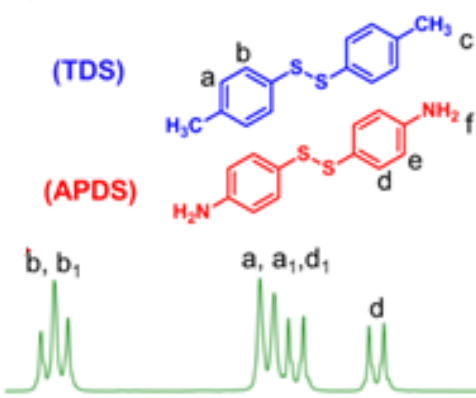

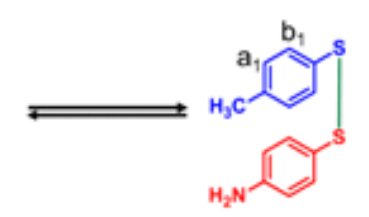

(TDS + APDS, $24 \mathrm{~h}$ )
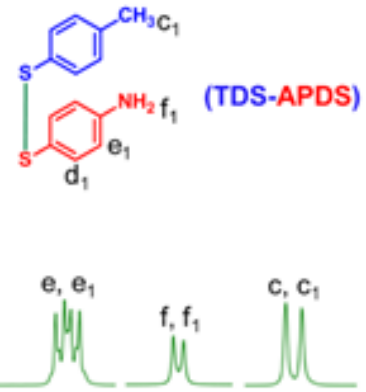

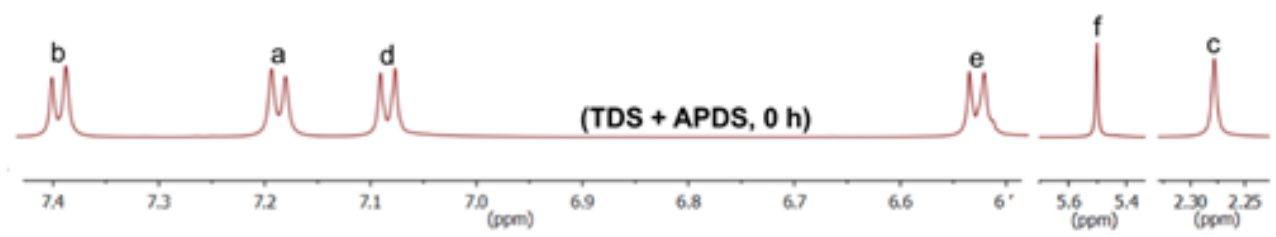

43 Figure S7. Zoomed ${ }^{1} \mathrm{H}-\mathrm{NMR}$ spectra of the equimolar mixture of TDS and APDS at $0 \mathrm{~h}$ and $4424 \mathrm{~h}$. 
<smiles>Cc1ccc(SSc2ccc(N)cc2)cc1</smiles><smiles>Cc1ccc(SSc2ccc(N)cc2)cc1</smiles>

$$
\mathrm{b}_{1} \begin{array}{cc}
\mathrm{a}_{1} \\
\mathrm{a}_{1}
\end{array}
$$

b a

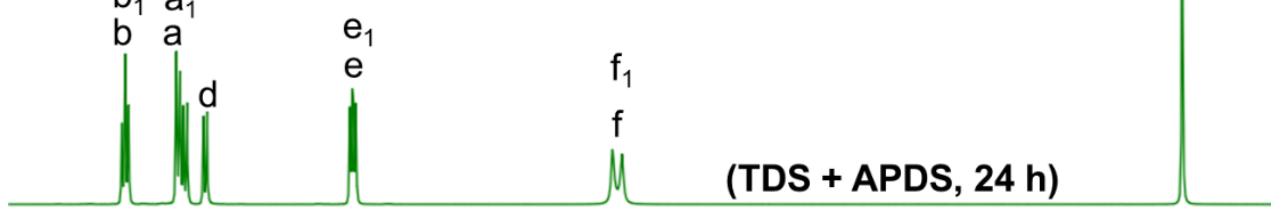

DMSO

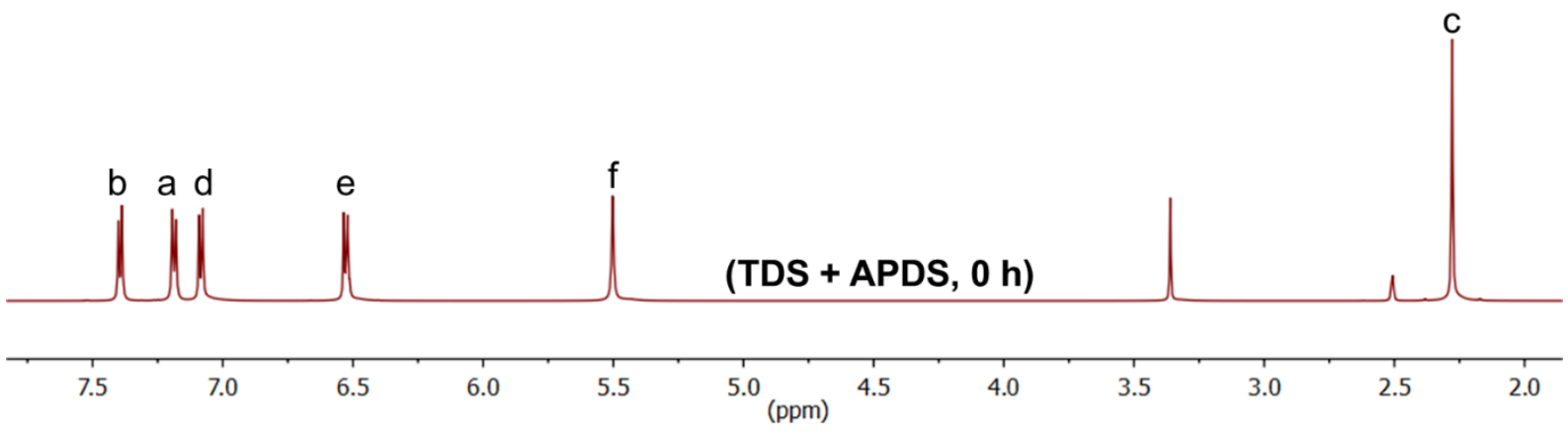

45

Figure S8. ${ }^{1} \mathrm{H}-\mathrm{NMR}$ spectra of the equimolar mixture of TDS and APDS at $0 \mathrm{~h}$ and $24 \mathrm{~h}$.

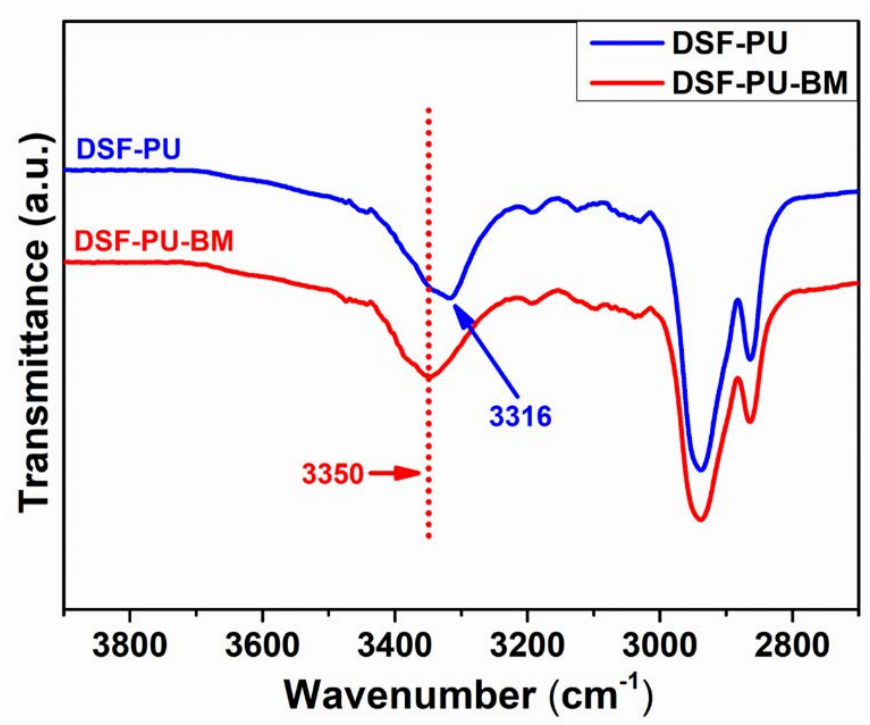

Figure S9: FT-IR amplified spectra of DSF-PU, DSF-PU-BM in range of 2700-3900 $\mathrm{cm}^{-1}$ 

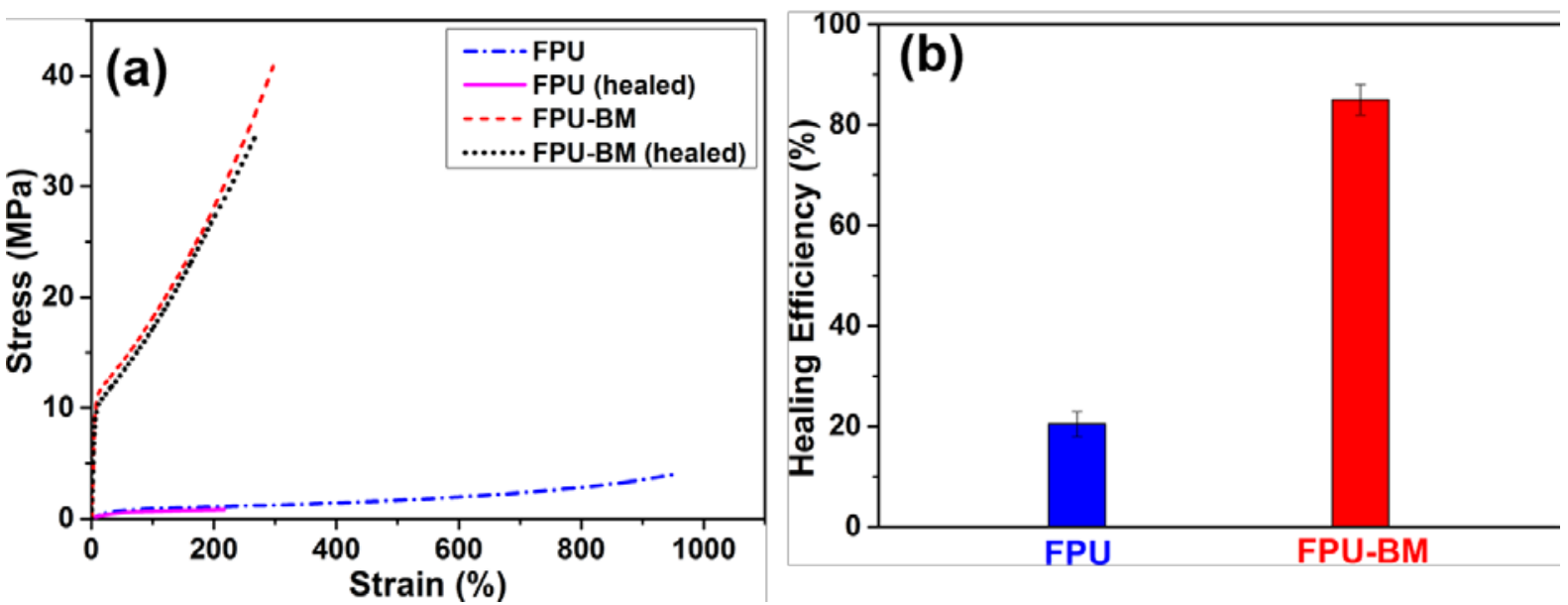

51 Figure S10: Stress-strain curves of the original and healed samples (a) and healing efficiency

52 (b) of FPU and FPU-BM. 